\title{
A feitura da Bíblia: dos primeiros fragmentos à Sagrada Escritura
}

\author{
The Making of the Bible: From the First
}

Fragments to Sacred Scripture

KONRAD SCHMID (iDa

\section{Resumo}

A Bíblia é uma obra de escribas, em geral anônimos, que a produziram como texto escrito entre o século IX AEC e o século II EC. Suas tradições orais se estendem até o segundo milênio AEC. O resultado desta história longa de composição é um texto complexo, porém legível, como demonstra sua longa história de recepção, principalmente no judaísmo e no cristianismo. Se olhada de perto, a Bíblia revela um interessante conjunto de pesos e contrapesos entre suas posições teológicas. Parece que os autores não se preocuparam sempre com a consistência narrativa mas, antes, com a criação de um universo literário que inclui uma variedade de perspectivas teológicas.

Palavras-chave: Bíblia. Crítica bíblica. Bíblia hebraica. Cultura de escribas. Antigo Israel.

\section{Abstract}

The Bible is a work of foremost anonymous scribes who produced it as a written text between the 9th century BCE and the 2nd century CE. Its oral traditions even reach back into the 2nd millennium BCE. The result of this long composition history is a complex, yet readable text, as its long reception history, foremost in Judaism and Christianity, demonstrate. If read closely, the Bible reveals an interesting set of checks and balances between its theological positions. It seems that its authors were not always concerned

\footnotetext{
a Universidade de Zurique, Zurique, Suíça. Doutor e Livre-Docente em Teologia, e-mail: konrad.schmid@theol.uzh.ch

Tradução: Luís Marcos Sander
} 
with narrative consistence in the first place, but with creating a literary universe that includes a variety of theological perspectives.

Keywords: Bible. Biblical Criticism. Hebrew Bible. Scribal Culture. Ancient Israel.

\section{A Bíblia e sua feitura}

A feitura da Bíblia - algumas pessoas já ficariam surpresas com a formulação do título de minha palestra. A Bíblia tem uma feitura? A Bíblia tem uma história? A Bíblia foi feita, assim como outros artefatos literários o foram?

Sim, é isso mesmo. Já na Antiguidade havia um conhecimento claro acerca do fato de que seres humanos específicos escreveram os textos bíblicos em lugares específicos e em épocas específicas. Uma das mais famosas passagens a esse respeito provém do Talmude babilônico, uma extensa coleção de leis, ditos e relatos judaicos que foi registrada por escrito na Antiguidade tardia:

Quem escreveu as Escrituras? - Moisés escreveu seu próprio livro e o trecho de Balaão e Jó. Josué escreveu o livro que leva seu nome e [os últimos] oito versículos do Pentateuco. Samuel escreveu o livro que leva seu nome e o Livro de Juízes e Rute. Davi escreveu o Livro dos Salmos, incluindo nele a obra dos anciãos, a saber, Adão, Melquisedeque, Abraão, Moisés, Hemã, Jedutum, Asafe e os três filhos de Corá. Jeremias escreveu o livro que leva seu nome, o Livro dos Reis e Lamentações. Ezequias e seus colegas escreverem Isaías, Provérbios, o Cântico dos Cânticos e Eclesiastes. Os Homens da Grande Assembleia escreveram Ezequiel, os Doze Profetas Menores, Daniel e o Rolo de Ester. Esdras escreveu o livro que leva seu nome e as genealogias do Livro de Crônicas até sua própria época. [...] Quem, então, o [Livro de Crônicas] concluiu? Neemias, filho de Hacalias (BB 14b-15a).

Este texto, como toda passagem dentro do Talmude, é muito difícil de datar, mas talvez seja proveniente do século III AEC. Ele demonstra claramente que, mesmo em tempos antigos, estudiosos como os autores do Talmude Babilônico desenvolveram teorias a fim de entender quando e por quem a Bíblia foi escrita. Observe-se particularmente que, em alguns pontos, o próprio Talmude se distancia das atribuições de autoria bíblicas: por exemplo, Ezequias e seus colegas escreveram Isaías, e os Homens da Grande Assembleia escreveram Ezequiel. Naturalmente, parece haver uma distinção aqui entre 
"escrita", isto é, autoria, e "registrar por escrito", isto é, colocar no papel algo já existente. Não obstante, é notável que o Talmude tenha uma visão diferenciada da forma como os escritos bíblicos surgiram.

Isso também se aplica à própria Bíblia. A Bíblia não só tem uma história literária na perspectiva da pesquisa bíblica, mas seus livros também apresentam uma história literária própria: com frequência, seus escritos são atribuídos a certas figuras da história bíblica que, às vezes, são acurados, ao menos no tocante ao cerne literário desses livros, p. ex., a maioria dos livros proféticos como Isaías, Jeremias, Ezequiel, etc. Em muitos outros casos, porém, essas atribuições são historicamente incorretas, p. ex. a atribuição explícita de alguns trechos do Pentateuco a Moisés (há de fato apenas seis passagens na Torá que reivindicam uma autoria mosaica para trechos específicos, relativamente breves, ao passo que a Torá, de modo geral, não afirma ter sido escrita por Moisés), a atribuição de muitos salmos a Davi, a suposta autoria do Qohelet, do Cântico dos Cânticos ou de algumas partes de Provérbios por parte de Salomão. Mas nessa época não é importante se essas teorias bíblicas são historicamente acuradas ou não; é importante, isto sim, perceber que a Bíblia não se apresenta como um livro atemporal de autoria divina rigorosa, como, p. ex., o faz o Corão, mas é formado como uma biblioteca que reivindica ter suas origens em diferentes períodos da história de Israel e ter sido composta por diferentes autores, embora muitos livros bíblicos permaneçam anônimos no tocante à sua suposta autoria.

Portanto, perguntar a respeito da "feitura da Bíblia" não é algo estranho à própria Bíblia. Ela mesma se apresenta ou ao menos sugere que sua feitura é um tema relevante e está interessada na história de sua gênese!

\section{A distinção entre o mundo da narrativa e o mundo do narrador}

É crucial, entretanto, introduzir uma distinção muito básica para explorar a questão da feitura da Bíblia: trata-se da distinção entre o mundo da narrativa e o mundo do narrador. Permitam-me ilustrar essa distinção brevemente com um exemplo não bíblico tirado de meu país natal, a Suíça. A peça de Friedrich Schiller sobre o herói nacional suíço Guilherme Tell se 
desenrola na Suíça do século XIII, e este é o mundo da narrativa. O mundo de seu narrador, entretanto, é a Alemanha de fins do século XVIII. Suponho que não seja surpreendente que do Guilherme Tell de Friedrich Schiller se possa aprender mais sobre a Alemanha do século XVIII do que sobre a Suíça do século XIII. A Bíblia pode ser comparada a isso. No tocante à Bíblia hebraica, à qual irei me limitar no que se segue porque ela é minha área de especialidade, o mundo de sua narrativa se estende da criação do mundo (há cerca de seis mil anos, de acordo com a Bíblia) até o período persa, sendo que os últimos acontecimentos relatados por ela dizem respeito à missão de Esdras e Neemias no século V ou IV a.C.

O mundo de seus narradores - e aqui estou falando apenas das versões escritas dos relatos bíblicos, não de seus possíveis precursores orais - é significativamente diferente daquele período de tempo, embora haja alguma sobreposição: os mais antigos textos bíblicos provavelmente datam do século IX AEC, e os últimos contidos na Bíblia hebraica, talvez do século II AEC, como irei mostrar mais detalhadamente abaixo. Em outras palavras, se lemos o livro de Gênesis, que se situa basicamente no $4^{\circ}$ ao $2^{\circ}$ milênio $A E C$, ficamos sabendo muito mais sobre o $1^{\circ}$ milênio $A E C$ em que ele foi escrito do que dos milênios anteriores em que os cenários de suas narrativas estão localizados. Em seus relatos, a Bíblia hebraica muitas vezes reflete experiências de gerações posteriores que projetaram seus conceitos teológicos para dentro do passado distante e primitivo. Isso não tem nada a ver com uma tentativa de adulterar a história na Bíblia, mas tem a ver com o pensamento mitológico. Os mitos lidam com questões referentes à essência como questões relacionadas à origem. Para explicar alguma coisa, explica-se como algo surgiu da maneira como é. E o algo mais básico é o quanto antes surgiu, segundo o pensamento mitológico. Por isso, muitas questões fundamentais referentes à identidade religiosa, étnica, cultural ou política com as quais os autores bíblicos lidaram são tratadas nos primeiros capítulos ou no primeiro livro da Bíblia: Por que cai chuva do céu? Por que temos que trabalhar? Por que as mulheres têm que entrar em trabalho de parto ao dar à luz? Por que não vivemos no paraíso ou ao menos perto de Deus? Por que os seres humanos comem animais? Por que há povos e línguas diferentes? Essas questões e suas respostas foram relegadas aos primórdios 
da história do mundo ou ao início da história de Israel para mostrar que elas constituem os fundamentos básicos sobre os quais nos encontramos e dos quais dependemos. Para o pensamento bíblico, não é o que aconteceu primeiro que vem em primeiro lugar, e sim o que é mais importante é que vem em primeiro lugar.

Essa também é a razão pela qual muitos livros proféticos incluem textos que não remontam aos próprios profetas, mas são resultado de interpretações e ampliações posteriores. Muitas vezes, eles surgiram ao longo de séculos, tendo sido escritos por um número significativo de escribas que não tinham interesse em revelar sua identidade ou seu nome, mas preferiam escrever em nome de Isaías, Jeremias, Ezequiel, etc., usando, assim, a autoridade desses personagens. O livro de Jeremias até fala explicitamente sobre o fato de que foi expandido gradativamente. Em Jr 36.32, depois de o rei Jeoaquim ter queimado o rolo que continha as palavras de Jeremias, é dito o seguinte:

Então Jeremias pegou outro rolo e o deu a Baruque, filho de Nerias, o escrivão, o qual escreveu nele, conforme Jeremias ia ditando, todas as palavras do rolo que Jeoaquim, rei de Judá, havia queimado. E ainda se acrescentaram a elas muitas palavras semelhantes.

Os escribas dos livros proféticos estavam comprometidos tanto com a preservação quanto com a atualização das tradições que tinham em mãos. Aleida e Jan Assmann descreveram esse processo como uma abordagem integrada de "cultivo do texto" (Textpflege, no original em alemão) e "cultivo do sentido" (Sinnpflege, no original; ver ASSMANN; ASSMANN, 1987, p. 7-27, especialmente p. 12-13), isto é, os escribas da Bíblia hebraica não estavam preocupados apenas em transmitir o texto, mas também em cuidar de seu sentido, o que acarretava contínua atualização, revisão e ampliação. 0 resultado desse empreendimento dos escribas foi, é claro, um texto muito complexo que agora inclui diferentes perspectivas e posições sobre uma ampla variedade de temas e assuntos que é muito difícil de ler e produziu um grande número de abordagens hermenêuticas da Bíblia, que agora estão documentadas na rica história de sua recepção (ver ZIOLKOSWKI et al., 2007SS.). 


\section{A Bíblia não foi escrita como Bíblia}

A Bíblia não foi escrita como Bíblia. Se com a palavra "Bíblia" designamos uma coletânea canônica que é considerada Sagrada Escritura, então - a partir de uma perspectiva histórica — é um fato estabelecido com segurança que os escritos que acabaram fazendo parte da Bíblia não eram considerados "bíblicos" quando foram compostos. Isto se evidencia imediatamente ao olharmos, por exemplo, as cartas de Paulo, mas também se aplica aos Salmos, às leis e narrativas contidas no Pentateuco, aos Provérbios, etc. Eles foram escritos como textos, mas não como textos sagrados. Tanto o fenômeno chamado "Bíblia" quanto o termo "Bíblia” são, para falar sem rodeios, conceitos pós-bíblicos. A história literária e a história do cânone da Bíblia não coincidem. Elas se sobrepõem até certo ponto, mas os livros da Bíblia se originaram como coletâneas ou coleções de narrativas, leis, cânticos, ditos proféticos e sapienciais, e foi só no decorrer de um processo longo e complexo que esses escritos passaram a ser considerados Sagrada Escritura. É crucial perceber que o processo de canonização da Bíblia não é primordialmente uma questão de produção dos livros bíblicos, e sim de sua recepção: um livro bíblico não passa a integrar o cânone porque reivindica ou pretende ser canônico, e sim porque seus leitores o consideram merecedor de fazer parte do cânone. As coletâneas que acabaram se tornando a "Bíblia judaica" ou a "Bíblia cristã" contêm os livros que estavam sendo usados no culto e na liturgia. Seu delineamento exato só se tornou claro após um longo processo de deliberação dentro das comunidades religiosas judaica e cristã.

O termo “Bíblia” se deriva da expressão grega ta biblia, que é um plural e significa literalmente "livros". Foi apenas na Idade Média incipiente, no século IX, que o termo "Bíblia” se tornou a designação comum das Escrituras Sagradas do judaísmo e do cristianismo. É claro que o termo grego já era usado anteriormente, mas ainda não era um termo fixo. 


\section{As provas textuais para a Bíblia hebraica}

Qual é a base textual para a Bíblia hebraica (cf. LANGE, 2016, p. 121-195)? Quais são os mais antigos manuscritos que temos? Como é que chegamos a saber que se trata de um texto antigo? Deve-se mencionar em primeiro lugar o chamado Codex Leningradensis ou B 19 A (cf. TOV, 2012, p. 23-74). Este manuscrito da Bíblia hebraica data do ano 1008 EC. Trata-se de um texto medieval, mas ele constitui o mais antigo testemunho textual completo do Pentateuco. Isso parece nos deixar em uma posição muito incômoda: estamos lidando com um texto que se supõe ter 2.500 anos, mas sua atestação textual mais antiga só tem 1.000 anos. Entretanto, a situação não é irremediável.

Em primeiro lugar, há traduções antigas de uma data significativamente o anterior ao Códice B 19 A. As primeiras são os grandes códices da tradução da Bíblia hebraica para o grego, sendo o Codex Sinaiticus o mais antigo deles (cf. PARKER, 2010). Embora este texto não seja um original, é um bom testemunho do texto hebraico que está por trás dele, datando do século IV EC.

Em segundo lugar, há trechos mais antigos da Bíblia hebraica que foram preservados. Antes de 1947, o mais antigo fragmento de um texto bíblico existente era o chamado Papiro Nash, que data provavelmente de cerca de 100 ACE e contém tanto o Decálogo quanto o "Shema Israel" (isto é, "Ouve, ó Israel”) de Deuteronômio 6, que é uma das mais importantes orações judaicas até os dias de hoje ${ }^{1}$.

Muito mais importantes foram as descobertas de textos do Mar Morto que tiveram início em 1947 (cf. LANGE, 2009; XERAVITS; PORZIG, 2015, p. 2347). Descobriram-se remanescentes de cerca de 900 rolos, entre os quais havia muitos textos bíblicos. Eles podem ser datados principalmente dos séculos II e I AEC. A maioria desses textos são fragmentários, e muitos não têm uma dimensão maior do que alguns centímetros quadrados. Todos os fragmentos bíblicos podem ser acessados com facilidade no livro The Biblical Qumran Scrolls, de Eugene Ulrich (2010).

\footnotetext{
1 Ver TOV, 2012, p. 111. Entretanto, este texto é mais "litúrgico" do que "bíblico" em sua natureza.
} 
O que esses textos de Qumrã revelam sobre a Bíblia hebraica nos primórdios do período pós-bíblico? A percepção mais importante é a notável proximidade desses fragmentos, na medida em que foram preservados, com o Códice B 19 A. No caso do texto de Gn 1.1-5 em 4QGen bor poxemplo, não há quaisquer diferenças no texto consonantal (cf. ULRICH, 2010, p. 1-2). O texto preservado do fragmento está em vermelho, e ele é totalmente idêntico ao que temos no Codex Leningradensis.

Assim, os achados de Qumrã demonstram o seguinte: por um lado, podemos depositar uma confiança considerável no texto hebraico da Bíblia atestado no manuscrito medieval do Códice B 19 A, que constitui a base textual para a maioria das edições modernas da Bíblia. Por outro lado, naquela época ainda não havia, mesmo assim, um texto plenamente estável da Bíblia hebraica no sentido de que cada letra ou palavra estivesse fixada como parte de um texto plenamente canonizado, como mostram algumas pequenas diferenças entre os rolos (cf. também GRABBE, 2006, p. 319-338).

Em termos da composição da Bíblia hebraica, outra percepção que podemos deduzir de Qumrã é que a Bíblia hebraica foi basicamente terminada até fins do século II AEC. Alguns de seus textos com certeza são mais antigos, mas provavelmente nenhum deles é posterior ao século II AEC.

Um dado epigráfico relacionado a nosso interesse aqui deveria ser mencionado: há um texto quase-bíblico dos tempos bíblicos, que são os amuletos de prata de Ketef Hinnom, que contêm um texto próximo de $\mathrm{Nm}$ 6.24-26, a chamada "bênção aaraônica", e datam de algum ponto entre os séculos VII e II AEC. Mas neste caso não se trata de um testemunho para um texto "bíblico" (cf. BERLEJUNG, 2008a, p. 37-62; 2008b, p. 204-230). 


\section{Quem escreveu a Bíblia hebraica? A cultura dos escribas do Israel Antigo}

Como deveríamos imaginar o pano de fundo cultural e histórico da composição da Bíblia?² A primeira pergunta a se fazer neste tocante é: quem sabia efetivamente ler e escrever? Há diferentes estimativas sobre o mundo da Antiguidade, mas elas concordam que provavelmente não mais do que 5 a 10\% da população eram pessoas alfabetizadas a ponto de poder ler e escrever textos com alguma extensão. A alfabetização era, provavelmente, um fenômeno da elite, e textos circulavam apenas entre esses círculos, que se centravam em torno do palácio e do templo³. Nos tempos bíblicos, a produção de literatura era um empreendimento restrito sobretudo aos escribas profissionais, e a leitura de literatura estava geralmente limitada aos mesmos círculos que a produziam.

Israel Finkelstein e outros sustentaram que os óstracos de Laquis, provenientes, em parte, de um posto avançado militar, mostram ao menos seis escritas diferentes, o que aponta para uma alfabetização mais disseminada, até mesmo entre soldados no início do século VI AEC (FAIGENBAUM-GOLOVIN et al., 2016, p. 4664-4669). Mas esse tipo de prova continua sendo discutível.

Diversos pesquisadores (KEEL, 2007, p. 101-132; RICHELLE, 2016; SCHNIEDEWIND, 2019) defenderam a existência de uma tradição literária contínua em Jerusalém desde a Idade do Bronze da cidade-Estado até o início da Idade do Ferro. Embora essa perspectiva não seja, provavelmente, inteiramente errônea, ela não deveria ser superestimada. A Jerusalém de Abdi Hepa em meados do $2^{\circ}$ milênio AEC era algo diferente da Jerusalém de Davi ou Salomão, e houve, obviamente, uma ruptura cultural entre a Jerusalém da Idade do Bronze tardia e a da Idade do Ferro incipiente. Um exemplo pertinente seria a inscrição de Ofel, em Jerusalém, que mostra um nível

\footnotetext{
2 ROLLSTON, 2010. Cf. também TAPPY; MCCARTER, 2008; RICHELLE, 2016, p. 556-594; BLUM, 2016a, p. 21-52; BLUM, 2019, p. 3-44; GRUND-WITTENBERG, 2017, p. 327-345; FINKELSTEIN, 2020, p. 269-282.

${ }^{3}$ Cf., por exemplo, ROLLSTON, 2010, p. 127-133; CARR, 2005, p. 70-71, 165-166, 172-173, $187-$ 191; 2011, p. 128-129; HEZSER, 2001. ALEXANDER, 2003, p. 3-25, conta com uma ampla alfabetização entre os membros da comunidade de Qumrã.
} 
bastante rudimentar de educação linguística (LEHMANN; ZERNECKE, 2013, p. 437-450).

Uma segunda pergunta é: como as pessoas escreviam? A maioria das inscrições que temos estão em fragmentos de cerâmica ou pedra, mas isso é só o que sobreviveu. Por razões óbvias, textos em pedra ou barro duram muito mais tempo do que aqueles em papiro ou couro, de modo que não podemos simplesmente extrapolar a partir do que os arqueólogos encontraram para tirar conclusões acerca do material sobre o qual as pessoas em geral escreviam ${ }^{4}$. Além disso, temos um número impressionante de selos e bulas ou sinetes de Jerusalém durante o período do Primeiro Templo com resquícios de papiro sobre eles que provam que o papiro era um meio ou suporte comum usado para a escrita. Em alguns dos sinetes se encontram nomes como "Gemaryahu ben Shafan" [Gemarias, filho de Safã], que é mencionado em Jr 36.10, ou "Yehuchal ben Shelamayahu" [Jucal, filho de Semelias] e "Gedaliah ben Pashhur" [Gedalias, filho de Pasur], que conhecemos de Jr 38.1 (cf. RICHELLE, 2016).

É bem provável que o material usado para a escrita de textos como esses no Pentateuco tenha sido papiro ou couro: livros mais extensos precisavam ser escritos em couro, porque as folhas de papiro são frágeis. A tinta era composta de fuligem e metal. Os pesquisadores estimam que um escriba profissional levava seis meses para copiar um livro com a extensão de Gênesis ou Isaías. Caso se acrescente o valor das peles de carneiro, fica evidente quão cara deve ter sido a produção de um rolo desses.

Nos tempos bíblicos, o número de cópias dos livros da Bíblia provavelmente era muito pequeno. Quanto ao século II AEC, 2 Macabeus 2.1315 proporciona uma prova de que a comunidade judaica em Alexandria, que provavelmente estava entre os maiores grupos da diáspora, não possuía uma cópia de cada livro bíblico em sua biblioteca. Este texto cita uma carta dos jerosolimitas aos judeus de Alexandria que os convida a tomar emprestada uma cópia dos livros bíblicos de Jerusalém que eles não possuem.

\footnotetext{
${ }^{4}$ Com efeito, há uma única folha de papiro proveniente da época da monarquia: Mur 17, disponível em DE VAUX et al., 1955ss., v. 2, p. 93-100.
} 
Neemias [...] fundou uma biblioteca e reuniu os livros referentes aos reis e aos profetas, e os escritos de Davi. [...] Da mesma forma, também Judas (Macabeu) recolheu todos os livros que tinham sido extraviados por causa da guerra que nos foi feita, e eles estão em nossas mãos. Se, pois, deles precisardes, enviai-nos pessoas que vos possam levá-los (2 Mac 2.13-15).

O conhecimento histórico sobre os escribas e suas escolas no Israel antigo é muito limitado. Tanto provas tiradas da Bíblia quanto selos (e impressões de selos; cf. RICHELLE, 2016, p. 556-594) sobreviventes do período pré-exílico atestam suficientemente a existência de escribas profissionais (cf., p. ex., 2Sm 8.17; 1Rs 4.3; Jr 32; 36; 43; 45 [“Baruque, o escriba”]; Ed 7.6,12-26 ["Esdras, o escriba da lei do Deus do céu”]; Ne 13.12-13; Eclo [Sir] 38-39; Mc 11.27-33; Mt 23). A função deles mudou ao longo da história, indo na direção dos estudos relacionados à atividade do escriba, o qual não era apenas responsável pelo registro de textos (embora isso tenha permanecido necessário por causa da durabilidade limitada dos meios ou suportes textuais), mas também pela interpretação ampliadora dos textos que transmitiam (cf. Jr 36.32).

À luz de analogias culturais e históricas semelhantes, pode-se supor a existência de escribas formados em escolas localizadas junto ao templo ou ao palácio. A Bíblia quase não menciona essas escolas (só Eclo 51.23; At 19.9), de modo que elas precisam ser deduzidas de situações análogas, o que não depõe necessariamente contra essa hipótese. Tampouco havia uma separação rigorosa entre as escolas do templo e as do palácio. O templo não era uma instituição autônoma, mas dependia da corte real.

A tradição talmúdica sabe da existência de 480 escolas em Jerusalém (y. Meg. 73b), o que, entretanto, talvez seja exagerado. De qualquer modo, provavelmente havia um número significativo de escolas em atividade, especialmente em Jerusalém, a partir do início do período helenístico. Não se precisa necessariamente imaginar um prédio à parte para essas escolas. O que era central era a relação entre mestre e aluno (1Cr 25.8; Pv 5.12-14; Sl 119.99). A instrução dos alunos poderia ter ocorrido nos recintos do templo ou na residência privada dos mestres. Deveríamos esperar que houvesse bibliotecas privadas entre famílias sacerdotais, que tinham certa importância na transmissão do conhecimento dos escribas dentro da família. 
Há pesquisadores que às vezes consideram significativa a ausência de menção de escolas em fontes israelitas antigas e atribuem a formação dos escribas, em vez disso, à transmissão de conhecimentos dentro de "famílias" de escribas. Provavelmente se deveriam combinar as duas hipóteses, e não vêlas como mutuamente excludentes 5 .

\section{Como podemos datar textos bíblicos?}

Quando a Bíblia hebraica foi composta? Visto que ela se desenvolveu como um empreendimento colaborativo entre escribas, não se pode indicar uma única data, mas só é possível determinar um período de tempo no qual seus textos foram escritos. Um esclarecimento importante se faz necessário quanto ao terminus a quo ("data a partir da qual”). Nós só podemos determinar os inícios das mais antigas versões escritas de um texto. Em outras palavras, isso não inclui a pré-história oral de um texto. Muitos textos bíblicos remontam a tradições orais que podem ser muito mais antigas do que seus equivalentes escritos. Portanto, o terminus a quo só determina o início da transmissão escrita de um texto que, por sua vez, talvez já fosse conhecido como uma narrativa oral ou algo semelhante (cf. STECK, 1995, p. 65-78; WAHL, 1997).

Muitos, mas nem de longe todos os textos bíblicos mencionam datas de autoria, por exemplo nos sobrescritos dos livros proféticos. Mas essas atribuições não podem ser tomadas ao pé da letra em termos históricos, e, de qualquer forma, é necessário encontrar outras abordagens para a literatura anônima da Bíblia, como é o caso da Torá. É preciso procurar indicadores internos e externos para determinar a data de sua composição.

Há uma observação básica que é relevante para se determinar os primórdios da formação literária da Bíblia. Podemos identificar com segurança uma ruptura histórica nos séculos IX e VIII AEC no desenvolvimento cultural de Israel e Judá. A essa altura, um certo nível de estatalidade e alfabetização tinha

\footnotetext{
${ }^{5}$ Ver, por exemplo, a família jerosolimita dos Chapanidas [Shapanids] que era próxima tanto à corte real quanto ao templo (cf. 2 Rs 22.3; Jr 36).
} 
sido alcançado, e esses dois elementos andam de mãos dadas. Isto é, quanto mais desenvolvido for um Estado, tanto mais burocracia e educação serão necessárias - especialmente na área da escrita.

Quando se considera o número de inscrições encontradas no Israel e Judá antigos, verifica-se que os números aumentam claramente no século VIII, e esse aumento provavelmente deveria ser interpretado como indicação de um desenvolvimento cultural ocorrido no Israel e Judá antigos. Essa afirmação pode ser corroborada examinando-se os textos que foram encontrados e podem ser datados no século X AEC, como, p. ex., o calendário de Gezer (cf., p. ex., PARDEE, 1997, p. 396-400; SIVAN, 1998, p. 101-105), o fragmento de cerâmica de Jerusalém (cf. LEHMANN; ZERNECKE, 2013, p. 437-450), a inscrição de Baal em Bete Semes (cf. MCCARTER; BUNIMOVITZ; LEDERMAN, 2011, p. 179193), o abecedário de Tel Zaite (cf. TAPPY; MCCARTER, 2008), e o óstraco de Khirbet Qeiyafa (cf. SCHROER; MÜNGER, 2017). Todos eles provêm de cerca do século X AEC. A modéstia de seu conteúdo e estilo de escrita são igualmente fáceis de discernir.

Se avançamos cerca de um século até o século IX AEC, os indícios são muito mais eloquentes, ainda que alguns deles estejam em aramaico e não em hebraico. A primeira estela monumental da região é a estela de Mesha [ou Mesa], que é escrita em moabita e contém a primeira referência extrabíblica documentada a Yahweh [Javé] e Israel assim como os conhecemos (cf. DEARMAN, 1989). Outro texto monumental é a estela de Tel Dã em aramaico, mais conhecida por mencionar a "Beth David" [casa de Davi] (cf. ATHAS, 2005; BLUM, 2016b, p. 37-56).

Outro elemento probatório é a inscrição em aramaico, do século VIII ACE, de Tel Deir Alla (WEIPPERT; WEIPPERT, 1982, p. 77-103; BLUM, 2008a, p. 33-53; 2008b, p. 573-601), que menciona o profeta Balaão que aparece em Números 22-24. O relato sobre Balaão que se encontra na inscrição é completamente distinto da narrativa sobre ele na Bíblia, mas continua sendo um dos mais antigos elementos probatórios para um texto literário na vizinhança próxima do Israel antigo.

Erhard Blum, juntamente com outros, defendeu convincentemente a interpretação do sítio de Tel Deir Alla como uma escola, por causa de um paralelo helenístico tardio à arquitetura construtiva de Thrimitis no Egito (de 
cerca do século IV EC; cf. BLUM, 2019, p. 3-44). Esta interpretação segundo a qual se trata de uma escola também pode se aplicar a Kuntillet Ajrud, onde também encontramos escritos na parede (cf. MESHEL, 2012).

O marco estabelecido nos séculos IX e VIII AEC pela grande quantidade e qualidade nova de textos escritos no Israel e Judá antigos corresponde a outra característica relevante. Por volta dessa época, Israel começa a ser percebido como um Estado por seus vizinhos. Não apenas mudanças internas ocorridas no desenvolvimento da escrita, mas também percepções externas contemporâneas indicam que Israel e Judá haviam atingido um nível de desenvolvimento cultural nos séculos VIII-IX AEC que possibilitava a produção de textos literários.

Alguns bons exemplos disso são as inscrições assírias de meados do século IX AEC que mencionam Jeú, o homem de Bit-Humri, que significa Jeú da Casa de Onri. O Obelisco Negro inclusive mostra Jeú em um retrato (inclinandose diante do rei assírio), que é a mais antiga imagem ainda preservada de um israelita (KEEL; UEHLINGER, 1994, p. 391-420). Com base nessas observações sobre o desenvolvimento de uma cultura dos escribas no Israel antigo, podemos supor que os mais antigos textos do Pentateuco tenham se originado como produções literárias dos séculos VIII e IX AEC.

Quando a Bíblia hebraica foi concluída? Quanto a essa questão, pelo menos três áreas de provas ou indícios deveriam ser mencionadas. Em primeiro lugar, temos as provas de Qumrã. Seus manuscritos bíblicos atestam o fato de que no final do século II ACE os livros bíblicos estavam basicamente concluídos. Há algumas pequenas variantes entre rolos diferentes do mesmo livro, mas essa situação poderia ser comparada a diferentes traduções da Bíblia que existem lado a lado atualmente: todas elas testemunham a mesma Bíblia, mas sua formulação pode diferir ligeiramente.

Em segundo lugar, há a tradução para o grego, a chamada Septuaginta, cujos primórdios podem ser datados em meados do século II AEC, ${ }^{6}$ e parece ter sido finalizada por volta de fins do século I EC.

\footnotetext{
${ }^{6}$ Cf. SIEGERT, 2001, p. 42-43. O mais antigo manuscrito do pentateuco grego é o papiro Rylands 458, de meados do século II AEC; cf. WEVERS, 1977, p. 240-244; DE TROYER, 2008, p. 277.
} 
Em terceiro lugar, o último elemento reconhecível da história política na Bíblia hebraica é a Revolta dos Macabeus nos anos de 167-164 AEC, que se reflete no livro de Daniel7 ${ }^{7}$. Alguns pesquisadores sustentam que há alguns salmos, como o Sl 110, que provêm do período hasmoneu, o que até seria 50 anos mais tarde, mas essas suposições são objeto de contestação.

Isso nos deixa com uma faixa histórica entre os séculos IX ou VIII AEC e meados do século II AEC para a composição da Bíblia hebraica. É claro que muitos de seus textos remontam a tradições orais anteriores, mas como textos escritos eles não são anteriores ao primeiro milênio AEC.

\section{Quando e como os escritos bíblicos se tornaram canônicos?}

É interessante observar que a primeira decisão oficial da igreja sobre o cânone bíblico só foi tomada em 1545, no Concílio de Trento, o Concilium Tridentinum. Nele, pela primeira vez na história da igreja, o cânone da Bíblia foi definido e decretado oficialmente - e a decisão foi motivada basicamente pelo desejo da Reforma de limitar o Antigo Testamento cristão aos livros da Bíblia hebraica, a hebraica veritas, e de não incluir em suas Bíblias as escrituras greco-judaicas do período do Segundo Templo, como Judite, Tobias, Ben Siraque [Eclesiástico] ou a Sabedoria de Salomão.

Mas, naturalmente, o cânone bíblico é mais antigo do que sua primeira atestação em um decreto da igreja oficial. O uso do termo "cânone" como referência à biblioteca bíblica é atestado a partir do século IV EC, porém o fenômeno de escritos bíblicos serem considerados autoritativos remonta a um período bem anterior à era da própria Bíblia, mas não a seus primórdios.

Aqui temos de fazer primeiro uma observação geral sobre 0 desenvolvimento da religião do Israel antigo. Durante os tempos bíblicos, a religião de Israel estava centrada em torno do culto no templo de Jerusalém e talvez, antes da reforma do rei Josias em 622 AEC, também em alguns outros

\footnotetext{
${ }^{7}$ A cronologia bíblica em Gn 5 e 11 pode apontar para uma reescrita, no período macabeu, da extensão do tempo de vida das figuras pré- e pós-dilúvio da Bíblia hebraica; cf. HUGHES, 1990, mas também as reservas de HENDEL, 2012, p. 448-464.
} 
santuários. A destruição do templo de Jerusalém em 587 AEC deu início à transformação da orientação cultual da religião de Israel. As pessoas que foram deportadas para a Babilônia não podiam mais participar do culto no templo e dependiam de suas tradições orais e escritas. Os elementos ligados aos escribas se tornaram cada vez mais importantes. A religião cultual de Israel começou a se transformar em uma religião vinculada a um livro, processo este que foi concluído mais tarde na segunda destruição do templo de Jerusalém em $70 \mathrm{EC}$, quando os romanos destruíram a cidade. O Segundo Templo também se perdeu, e o judaísmo e o cristianismo se tornaram religiões sem templo que também podem ser chamadas de religiões vinculadas a um livro. Passo a passo, as Escrituras Sagradas assumiram as funções que anteriormente eram cumpridas pelo culto no templo.

O cerne do cânone bíblico, particularmente do cânone da Bíblia hebraica, é a Torá. É bem possível que a Torá tenha se tornado um corpo de literatura autoritativa no período persa, isto é, nos séculos V ou IV AEC, quando os judeus no Império Persa foram solicitados a apresentar um corpo de leis segundo as quais estavam dispostos a viver. O Império Persa não tinha uma legislação imperial geral. Em vez disso, os persas deixaram que os povos subjugados vivessem de acordo com suas próprias regras, só que estas tinham de ser autorizadas pela corte persa. A autoridade da Torá talvez tenha tido início com essa função jurídica dentro do Império Persa, e o conceito de autoridade textual foi então, passo a passo, ampliado a outras partes do cânone bíblico, como os Profetas e os Escritos que surgiram em tempos helenísticos e romanos.

Resta salientar que o cânone bíblico cristão, com um Antigo e um Novo Testamentos, é um fenômeno extremamente notável dentro da história das religiões. A noção de um cânone duplo com duas partes, escritas originalmente em duas (ou, se incluirmos também o aramaico, em três) línguas diferentes é uma singularidade que não se conhece em nenhum outro lugar. Isto é tanto mais notável porque não há uma hierarquia clara entre os dois Testamentos na teologia cristã: o Antigo Testamento não foi subordinado ao Novo e o Novo não foi superordinado ao Antigo. Eles foram, isto sim, colocados lado a lado, e esse esquema criou uma hermenêutica muito criativa e bem-sucedida que é 
agora testemunhada na rica e incomparável história da recepção da Bíblia. Isto me leva ao último ponto:

\section{Como se deve ler a Bíblia?}

A Bíblia hebraica se desenvolveu ao longo dos séculos e foi escrita por muitas mãos. Uma prática de leitura específica é necessária para entender seus textos. A solução não pode consistir em desintegrar seus escritos em suas supostas partes constituintes e interpretar essas partes como entidades separadas, como parecem sugerir algumas linhas da pesquisa histórico-crítica. Dever-se-ia, pelo contrário, respeitar que expressões de incoerência ou contradição sejam preservadas principalmente por razões de tradição. Aparentemente, os compiladores e editores não priorizavam uma integração suave ou inconsútil. A principal diretriz dos compiladores da Bíblia hebraica não era criar uma narrativa alinhada e coerente, e sim integrar tanto quanto podiam a partir de tradições já existentes.

A forma específica como a Bíblia hebraica foi formada exige que os leitores participem da hermenêutica que está inserida no próprio texto. A Bíblia hebraica é um texto composto. Mas a tarefa da pesquisa vai além da mera reconstrução de diferentes camadas no desenvolvimento literário da Bíblia hebraica. É necessária uma abordagem hermenêutica para desenvolver uma forma de ler seu texto que leve em conta, respeite e mantenha as ambiguidades produzidas por seus autores e redatores, que são responsáveis pela natureza dinâmica tanto do próprio texto quanto da história de sua recepção (cf. NAJMAN, 2012, p. 497-518; FISCHER, 2013; BERNER, 2021).

A Bíblia hebraica precisa ser considerada como uma unidade textual orgânica - reconhecendo plenamente a complexidade da história de sua composição. A pesquisa atual sugere que o grupo dos leitores da Bíblia hebraica era a própria comunidade de seus autores, isto é, que os leitores são os compositores, compiladores e editores (cf. SCHMID, 2011, p. 116-120; 2019, p. 10-14; BLUM, 2019, p. 3-44). Na Antiguidade, compor significava registrar a tradição, mas também ler a tradição já existente e envolver-se com ela. Talvez os antigos escritores e leitores soubessem como esses textos surgiram. E eles estavam comprometidos com a preservação da diferença - e não com a 
produção de uma narrativa linear e inconsútil, mas sim com o encaminhamento dos leitores para que estes desenvolvessem seu próprio sentido a partir de uma base textual complexa, muitas vezes desigual e às vezes até contraditória.

Seria possível chamar essa evocação do sentido em uma nova dimensão de "leitura estereométrica" (cf. LANDSBERGER, 1965, p. 17). Muitas vezes, as interpretações teológicas da Bíblia hebraica não são explicitadas no texto. Elas surgem, isto sim, por meio do processo de recepção de seus leitores. Esta característica dos textos bíblicos é altamente significativa para sua estética literária. Os leitores são impelidos a formar conclusões sintetizadoras específicas durante o processo de leitura, sem identificar inequivocamente $o$ sentido textual.

Até certo ponto, ler a Bíblia pode ser comparado a olhar uma obra arquitetônica que também surgiu ao longo de séculos, como, p. ex., a Catedral de Siracusa, na Sicília:

Figura 1 - Catedral de Siracusa, Sicília

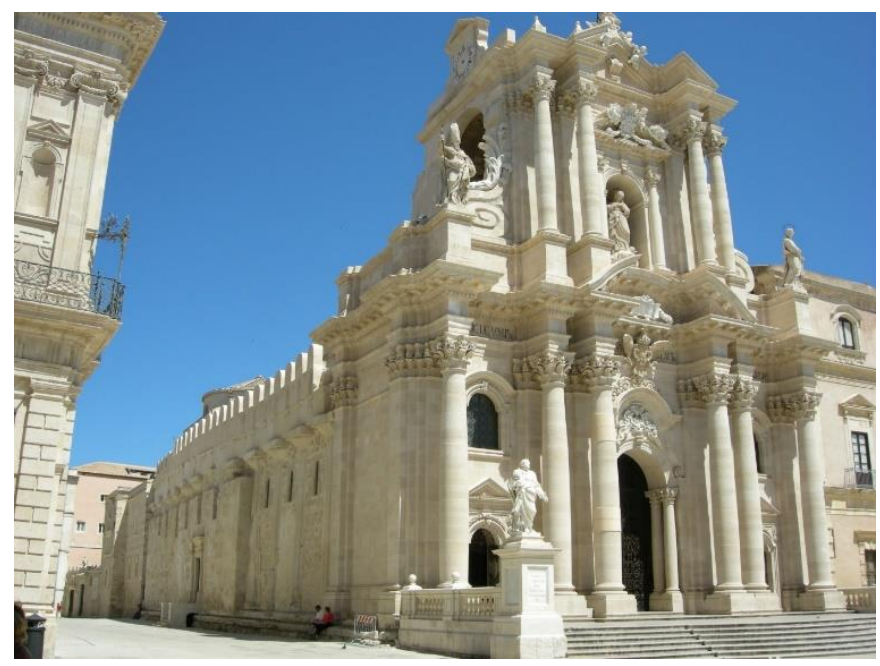

Fonte: SAILKO, 2009.

A Catedral de Siracusa (cf. GIANGRECO, 2009) remonta a um templo grego, dedicado à deusa Atena, que foi erigido no século $V A E C$. Os pilares do templo foram reutilizados e ainda são visíveis nas laterais da catedral atualmente. A partir do século VII EC foi construída uma basílica, reaproveitando o prédio que a antecedeu. Em 878, a igreja foi transformada 
em uma mesquita, mas foi reconvertida em 1085. Após um terremoto em 1693, a fachada barroca foi acrescentada à igreja. O resultado disso é um prédio muito diversificado que dá testemunho de sua história. Para o observador moderno, também é possível e até aprazível verificar as tensões e incoerências arquitetônicas do prédio que são responsáveis por sua beleza.

A leitura da Bíblia requer uma abertura semelhante para a percepção da diversidade, mas, como no caso da Catedral de Siracusa, envolver-se com esse tipo de complexidade é uma tarefa possível e gratificante. No caso da Bíblia, provavelmente é justo dizer que seu caráter com múltiplas camadas é uma das mais importantes razões do fato de ela ter sobrevivido ao longo dos séculos: a densidade da Bíblia enquanto texto, bem como o fato de ela ter incluído uma variedade de perspectivas diferentes a tornaram interessante para uma história de recepção contínua. Sem o processo constante de terem sido lidos, copiados e comentados, é provável que os livros da Bíblia hebraica tivessem sido esquecidos pouco tempo depois de sua composição e talvez só ficássemos sabendo dela por meio da possível coincidência de um achado arqueológico.

\section{Referências}

ALEXANDER, P. S. Literacy among Jews in Second Temple Palestine: Reflections on the Evidence from Qumran. In: BAASTEN, M. F. J.; VAN PEURSEN, W. T. (Orgs.). Hamlet on a Hill: Semitic and Greek Studies Presented to Professor T. Muraoka on the Occasion of his Sixty-Fifth Birthday. Leuven: Brill, 2003. p. 3-25.

ASSMANN, A.; ASSMANN, J. Kanon und Zensur. In: ASSMANN, A.; ASSMANN, J. (Orgs.). Kanon und Zensur: Archäologie der literarischen Kommunikation II. München: Fink, 1987. p. 7-27.

ATHAS, G. The Tel Dan Inscription: A Reappraisal and a New Interpretation. London: T\&T Clark, 2005.

BERLEJUNG, A. Der gesegnete Mensch. Text und Kontext von Num 6,22-27 und den Silberamuletten von Ketef Hinnom. In: BERLEJUNG, A.; HECKL, R. (Orgs.). Mensch und König. Studien zur Anthropologie des Alten Testament Rüdiger Lux zum 60. Geburtstag. Freiburg i.Br.: Herder, 2008a. p. 37-62.

BERLEJUNG, A. Ein Programm fürs Leben. Theologisches Wort und anthropologischer Ort der Silberamulette von Ketef Hinnom. Zeitschrift für die Alttestamentliche Wissenschaft, v. 120, p. 204-230, 2008b. 
BERNER, C. Gottes Wort und Schreibers Griffel. Die Redaktionsgeschichte alttestamentlicher Texte als Herausforderung für Exegese und Theologie. Zeitschrift für Theologie und Kirche, v. 118, p. 141-159, 2021.

BLUM, E. "Verstehst du dich nicht auf die Schreibkunst...?" Ein weisheitlicher Dialog über Vergänglichkeit und Verantwortung: Kombination II der Wandinschrift vom Tell Deir 'Alla. In: BAUKS, M.; LIESS, K.; RIEDE, P. (Orgs.). Was ist der Mensch, dass du seiner gedenkst? (Psalm 8,5). Aspekte einer theologischen Anthropologie. Festschrift für Bernd Janowski zum 65. Geburtstag. Neukirchen-Vluyn: Neukirchener, 2008a. p. 33-53.

BLUM, E. Die Kombination I der Wandinschrift vom Tell Deir 'Alla. Vorschläge zur Rekonstruktion mit historisch-kritischen Anmerkungen. In: KOTTSIEPER, I. et al. (Orgs.). Berührungspunkte: Studien zur Sozial- und Religionsgeschichte Israels und seiner Umwelt. Festschrift für Rainer Albertz zu seinem 65. Geburtstag. Münster: Ugarit, 2008b. p. 573-601.

BLUM, E. Die altaramäischen Wandinschriften aus Tell Deir 'Alla und ihr institutioneller Kontext. In: FOCKEN, F.-E.; OTT, M. (Orgs.). Meta-Texte. Erzählungen von schrifttragenden Artefakten in der alttestamentlichen und mittelalterlichen Literatur. Berlin: de Gruyter, 2016a. p. 21-52.

BLUM, E. The Relations between Aram and Israel in the 9th and 8th Centuries BCE. The Textual Evidence. In: SERGI, O.; OEMING, M.; DE HULSTER, I. J. (Orgs.). In Search for Aram and Israel. Politics, Culture, and Identity, Tübingen: Mohr Siebeck, 2016b. p. $37-56$.

BLUM, E. Institutionelle und kulturelle Voraussetzungen der israelitischen Traditionsliteratur. In: EBACH, R.; LEUENBERGER, M. (Orgs.). Tradition(en) im alten Israel. Konstruktion, Transmission und Transformation. Tübingen: Mohr Siebeck, 2019. p. 3-44.

CARR, D. M. Writing on the Tablet of the Heart: Origins of Scripture and Literature, Oxford: Oxford University Press, 2005.

CARR, D. M. The Formation of the Hebrew Bible: A New Reconstruction, Oxford: Oxford University Press, 2011.

CRÜSEMANN, F. Die Tora. München: Kaiser, 1992.

DEARMAN, J. A. (Org.). Studies in the Mesha Inscription and Moab. Atlanta: SBL, 1989.

DE TROYER, K. When Did the Pentateuch Come into Existence? An Uncomfortable Perspective. In: KARRER, M.; KRAUS, W. (Orgs.). Die Septuaginta. Texte, Kontexte, Lebenswelten, Internationale Fachtagung veranstaltet von Septuaginta Deutsch (LXX.D). Wuppertal 20.-23. Juli 2006. Tübingen: Mohr Siebeck, 2008. p. 269-286.

DE VAUX, R. et al. Discoveries from the Judean Desert. Oxford: Oxford University Press, 1955ss. 
FAIGENBAUM-GOLOVIN, S. et al. Algorithmic handwriting analysis of Judah's military correspondence sheds light on composition of biblical texts. Proceedings of the National Academy of Sciences of the United States of America, v. 113, n. 17, p. 46644669, 2016.

FINKELSTEIN, I. The Emergence and Dissemination of Writing in Judah. Semitica et Classica, v. 13, p. 269-282, 2020.

FISCHER, I. Von der Vorgeschichte zur Nachgeschichte: Schriftauslegung in der Schrift - Intertextualität - Rezeption. Zeitschrift für die Alttestamentliche Wissenchaft, v. 125, p. 143-160, 2013.

GIANGRECO, R. Templum Majus II Duomo Simbolo di Siracusa. Siracusa: Edessae, 2009.

GRABBE, L. L. The law, the prophets, and the rest: The state of the Bible in preMaccabean times. Dead Sea Discoveries, v. 13, p. 319- 338, 2006.

GRUND-WITTENBERG, A. Literalität und Institution: Auf der Suche nach lebensweltlichen Kontexten der Literaturwerdung im alten Israel. Zeitschrift für die Alttestamentliche Wissenschaft, v. 129, p. 327-345, 2017.

HENDEL, R. A Hasmonean Edition of MT Genesis? The Implications of the Editions of the Chronology in Genesis 5. Hebrew Bible and Ancient Israel, v. 1, p. 448-464, 2012.

HEZSER, C. Jewish Literacy in Roman Palestine. Tübingen: Mohr Siebeck, 2001.

HUGHES, J. Secrets of the Time Myth and History in Biblical Chronology. Sheffield: Sheffield Academic Press, 1990.

KEEL, O.; UEHLINGER, C. Der Assyrerkönig Salmanassar III. und Jehu von Israel auf dem Schwarzen Obelisken. Zeitschrift für Katholische Theologie, v. 116, p. 391-420, 1994.

KEEL, O. Die Geschichte Jerusalems und die Entstehung des Monotheismus. Göttingen: Vandenhoeck \& Ruprecht, 2007. v. 1.

LANDSBERGER, B. Die Eigenbegrifflichkeit der babylonischen Welt. In: LANDSBERGER, B.; VON SODEN, W. (Orgs.). Die Eigenbegrifflichkeit der babylonischen Welt: Leistung und Grenze babylonischer Wissenschaft, Darmstadt: WBG, 1965. p. 1-18.

LANGE, A. Die Handschriften biblischer Bücher von Qumran und den anderen Fundorten. Tübingen: Mohr Siebeck, 2009.

LANGE, A. From Many to One - Some Thoughts on the Hebrew Textual History of the Torah. In: GERTZ, J. C. et al. (Orgs.). The Formation of the Pentateuch. Tübingen: Mohr Siebeck, 2016. p. 121-195.

LEHMANN, R. G.; ZERNECKE, A. E. Bemerkungen und Beobachtungen zu der neuen Ophel Pithosinschrift. In: LEHMANN, R. G.; ZERNECKE, A. E. (Orgs.). Schrift und 
Sprache. Papers read at the 10th Mainz International Colloquium on Ancient Hebrew (MICAH). Mainz, 28-30 October 2011. Waltrop: Spenner, 2013. p. 437-450.

MCCARTER, K. P.; BUNIMOVITZ, S.; LEDERMAN, Z. An Archaic Ba'al Inscription from Tel Beth-Shemesh. Tel Aviv, v. 38, p. 179-193, 2011.

MESHEL, Z. (Org.). Kuntillet 'Ajrud (Horvat Teman). An Iron Age II Religious Site on the Judah-Sinai Border. Jerusalem: Israel Exploration Society, 2012.

NAJMAN, H. The Vitality of Scripture Within and Beyond the "Canon". Journal for the Study of Judaism, v. 43, p. 497-518, 2012.

PARDEE, D. "Gezer Calendar”. In: THE OXFORD ENCYCLOPEDIA OF ARCHAEOLOGY IN THE NEAR EAST. Vol. 2. New York: Oxford University Press, 1997. p. 396-400.

PARKER, D. C. Codex Sinaiticus: The Story of the World's Oldest Bible. London: Hendrickson, 2010.

ROLLSTON, C. Writing and Literacy in the World of Ancient Israel. Atlanta: SBL, 2010.

RICHELLE, M. Elusive scrolls: Could any hebrew literature have been written prior to the eighth century BCE? Vetus Testamentum, v. 66, p. 556-594, 2016.

SAILKO. Ortigia, duomo, facciata. Wikimedia.org, 15 jun. 2009. Disponível em: https://commons.wikimedia.org/wiki/File:Ortigia,_duomo,_facciata_01.JPG. Acesso em: 02 set. 2021

SCHMID, K. Authorship. I. Ancient Near East and Hebrew Bible/Old Testament. In: KLAUCK, H.-J.; LEPPIN, V.; MCGINN, B. (Orgs.). Encyclopedia of the Bible and Its Reception. Berlin/New York: De Gruyter, 2011. v. 3, p. 116-120.

SCHMID, K. A Historical Theology of the Hebrew Bible. Grand Rapids: Eerdmans, 2019.

SCHNIEDEWIND, W. M. The Finger of the Scribe: How Scribes Learned to Write the Bible. New York: Oxford University Press, 2019.

SCHROER, S.; MÜNGER, S. (Orgs.). Khirbet Qeiyafa in the Shephelah. Papers Presented at a Colloquium of the Swiss Society for Ancient Near Eastern Studies Held at the University of Bern, September 6, 2014. Fribourg: Academic Press, 2017.

SIEGERT, F. Zwischen Hebräischer Bibel und Altem Testament. Eine Einführung in die Septuaginta. Münster: Ugarit, 2001.

SIVAN, D. The Gezer Calendar and Northwest Semitic Linguistics. IEJ, v. 48, p. 101-105, 1998.

STECK, O. H. Old Testament Exegesis: A Guide to the Methodology, Atlanta: SBL, 1995. 
TAPPY, R. E.; MCCARTER, P. K. Literate Culture and Tenth-Century Canaan: the Tel Zayit Abecedary in Context. Winona Lake: Eisenbrauns, 2008.

TOV, E. Textual Criticism of the Bible. 3. ed. Minneapolis: Fortress Press, 2012.

ULRICH, E. The Biblical Qumran Scrolls. Leiden: Brill, 2010.

WAHL, H. M. Die Jakobserzählungen. Studien zu ihrer mündlichen Überlieferung, Verschriftung und Historizität, Berlin: de Gruyer, 1997.

WEIPPERT, H.; WEIPPERT, M. Die „Bileam“-Inschrift von Tell Der 'Alla. ZDPV, v. 98, p. 77-103, 1982.

WEVERS, J. W. The Earliest Witness to the LXX Deuteronomy. Catholic Biblical Quarterly, v. 39, p. 240-244, 1977.

XERAVITS, G. G.; PORZIG, P. Einführung in die Qumranliteratur. Die Handschriften vom Toten Meer. Berlin: de Gruyter, 2015.

ZIOLKOWSKI, E. et al. Encyclopedia of the Bible and its Reception (EBR). Berlin: De Gruyter, 2007ss. 